\title{
Adhesion Between Volcanic Glass and Spacecraft Materials in an Airless Body Environment
}

Stephen Berkebile, Kenneth W. Street, Jr., and James R. Gaier

Glenn Research Center, Cleveland, Ohio 


\section{NASA STI Program . . . in Profile}

Since its founding, NASA has been dedicated to the advancement of aeronautics and space science. The NASA Scientific and Technical Information (STI) program plays a key part in helping NASA maintain this important role.

The NASA STI Program operates under the auspices of the Agency Chief Information Officer. It collects, organizes, provides for archiving, and disseminates NASA's STI. The NASA STI program provides access to the NASA Aeronautics and Space Database and its public interface, the NASA Technical Reports Server, thus providing one of the largest collections of aeronautical and space science STI in the world. Results are published in both non-NASA channels and by NASA in the NASA STI Report Series, which includes the following report types:

- TECHNICAL PUBLICATION. Reports of completed research or a major significant phase of research that present the results of NASA programs and include extensive data or theoretical analysis. Includes compilations of significant scientific and technical data and information deemed to be of continuing reference value. NASA counterpart of peer-reviewed formal professional papers but has less stringent limitations on manuscript length and extent of graphic presentations.

- TECHNICAL MEMORANDUM. Scientific and technical findings that are preliminary or of specialized interest, e.g., quick release reports, working papers, and bibliographies that contain minimal annotation. Does not contain extensive analysis.

- CONTRACTOR REPORT. Scientific and technical findings by NASA-sponsored contractors and grantees.
- CONFERENCE PUBLICATION. Collected papers from scientific and technical conferences, symposia, seminars, or other meetings sponsored or cosponsored by NASA.

- SPECIAL PUBLICATION. Scientific, technical, or historical information from NASA programs, projects, and missions, often concerned with subjects having substantial public interest.

- TECHNICAL TRANSLATION. Englishlanguage translations of foreign scientific and technical material pertinent to NASA's mission.

Specialized services also include creating custom thesauri, building customized databases, organizing and publishing research results.

For more information about the NASA STI program, see the following:

- Access the NASA STI program home page at http://www.sti.nasa.gov

- E-mail your question via the Internet to help@ sti.nasa.gov

- Fax your question to the NASA STI Help Desk at $443-757-5803$

- Telephone the NASA STI Help Desk at 443-757-5802

- Write to: NASA Center for AeroSpace Information (CASI) 7115 Standard Drive Hanover, MD 21076-1320 
NASA/TM-2012-217221

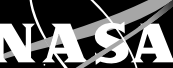

Adhesion Between Volcanic Glass and Spacecraft Materials in an Airless Body Environment

Stephen Berkebile, Kenneth W. Street, Jr., and James R. Gaier

Glenn Research Center, Cleveland, Ohio

Prepared for the

3rd Atmospheric and Space Environments Conference

sponsored by the American Institute of Aeronautics and Astronautics

Honolulu, Hawaii, June 27-30, 2011

National Aeronautics and

Space Administration

Glenn Research Center

Cleveland, Ohio 44135 


\section{Acknowledgments}

The authors thank Mike Weinstein of Zybek Advanced Products for supplying the synthetic noritic glass, Dave Hull for glass sample cutting, Joy Buehler for glass polishing, and Scott Panko and Rick Mondry for support in the laboratory.

Financial support was provided by NASA ETDP Thermal Control and Dust Mitigation Projects through the NASA Postdoctoral Program (administered by Oak Ridge Associated Universities).

Trade names and trademarks are used in this report for identification only. Their usage does not constitute an official endorsement, either expressed or implied, by the National Aeronautics and Space Administration.

Level of Review: This material has been technically reviewed by technical management.

Available from

NASA Center for Aerospace Information 7115 Standard Drive

Hanover, MD 21076-1320
National Technical Information Service 5301 Shawnee Road Alexandria, VA 22312 


\title{
Adhesion Between Volcanic Glass and Spacecraft Materials in an Airless Body Environment
}

\author{
Stephen Berkebile, Kenneth W. Street, Jr., and James R. Gaier \\ National Aeronautics and Space Administration \\ Glenn Research Center \\ Cleveland, Ohio 44135
}

\begin{abstract}
The successful exploration of airless bodies, such as the Earth's moon, many smaller moons of the outer planets (including those of Mars) and asteroids, will depend on the development and implementation of effective dust mitigation strategies. The ultrahigh vacuum environment (UHV) on the surfaces of these bodies, coupled with constant ion and photon bombardment from the Sun and micrometeorite impacts (space weathering), makes dust adhesion to critical spacecraft systems a severe problem. As a result, the performance of thermal control surfaces, photovoltaics and mechanical systems can be seriously degraded even to the point of failure. The severe dust adhesion experienced in these environments is thought to be primarily due to two physical mechanisms, electrostatic attraction and high surface energies, but the dominant of these has yet to be determined. The experiments presented here aim to address which of these two mechanisms is dominant by quantifying the adhesion between common spacecraft materials (polycarbonate, FEP and PTFE Teflon (DuPont), Ti-6-4) and a synthetic noritic volcanic glass, as a function of surface cleanliness and triboelectric charge transfer in a UHV environment. Adhesion force has been measured between pins of spacecraft materials and a plate of synthetic volcanic glass by determining the pull-off force with a torsion balance. Although no significant adhesion is observed directly as a result of high surface energies, the adhesion due to induced electrostatic charge is observed to increase with spacecraft material cleanliness, in some cases by over a factor of 10 , although the increase is dependent on the particular material pair. The knowledge gained by these studies is envisioned to aid the development of new dust mitigation strategies and improve existing strategies by helping to identify and characterize mechanisms of glass to spacecraft adhesion for norite volcanic glass particles. Furthermore, the experience of the Apollo missions revealed that dust mitigation strategies must be subjected to high fidelity tests. To facilitate the effectiveness of ground-based testing of mitigation strategies, the issue of a pressure limit for high fidelity tests will be addressed.
\end{abstract}

\section{Nomenclature}

$\theta$ torsion balance deflection angle

$\kappa$ torsion spring constant

$\tau$ torque

$U$ potential energy

\subsection{Introduction}

The development of dust mitigation strategies is important for the exploration of airless bodies in the Solar System, such as the lunar surface and the surfaces of asteroids, Mercury and the moons of Mars. This is because many critical spacecraft systems are sensitive to dust accumulation. When exposed to dust in vacuum, the performance of thermal control surfaces is seriously degraded (Ref. 1), photovoltaic 
efficiency is decreased (Refs. 2 and 3), mechanical systems are compromised through abrasion (Ref. 4) and optical elements of cameras and telescopes are scratched or occluded (Ref. 5). As a result, these and other systems may fail when operating in a dusty vacuum environment if effective mitigation strategies are not developed and implemented.

Under the conditions of ultrahigh vacuum ( $\mathrm{UHV},<10^{-9}$ torr) found at the surfaces of airless bodies, dust behaves very differently than in our atmosphere (Refs. 1 and 4). Dust adhesion properties are thought to be enhanced by two classes of mechanisms, increased surface energy and electrostatic attraction.

Firstly, particles of dust are made more reactive through "space weathering" processes caused by their exposure to high energy electromagnetic radiation and atomic or subatomic particle impacts, mainly from the Sun, as well as micrometeorite impacts (Refs. 1,6, and 7). Micrometeorite impacts create small dust particles and freshly fractured surfaces, whereas radiation and particle impacts create free radicals via electron ejection and dangling bonds at material lattice defect sites. These processes are referred to as dust "activation". In UHV environments, the atomic cleanliness of freshly fractured surfaces is maintained and the population of chemically reactive surface species remains significant due to the scarcity of molecules in the gas phase colliding with the surface of the dust. The particle bombardment of the dust (and, with exposure time, the spacecraft materials) in the UHV environment results in the absence of a thin film of hydrocarbons and water that exists on surfaces in our atmosphere. As a result, the adhesion of dust is enhanced up to two orders of magnitude, primarily due to van der Waals interactions (Refs. 7 to 9). Both chemical reactivity and cleanliness of the surfaces lead to an increased effective surface energy and can lead to increased adhesion. For example, between sapphire and aluminum, adhesion force was seen to be 13 times greater when cleaned in a UHV environment through ion bombardment than in ambient laboratory conditions (Ref. 10).

The second mechanism which can enhance dust adhesion arises from electrostatic forces. For example, most lunar particles are composed of nonconductive minerals and glasses and will build up a static charge under constant ion and photon bombardment (Ref. 11). The surface of the moon is positively charged on the side of the body facing the Sun (photoelectric effect) and negatively charged on the dark side (electrons from the solar wind) (Ref. 12).

It is unclear whether surface energy or electrostatic forces dominate for different particle sizes and for different types of dust, but both can lead to a strongly increased adhesion in UHV conditions. In order to develop the most effective mitigation strategies, the nature and strength of the adhesive forces must first be determined.

As a result of space weathering under UHV conditions, dust mitigation strategies which work under atmospheric conditions cannot be assumed to work on the surfaces of airless bodies, due to the mechanisms listed above which lead to an increased adhesion. As the Apollo missions have shown, even tests in low to high vacuum environments can lead to misleading results which do not accurately simulate the lunar environment (Ref. 1). An accurate pressure limit for high fidelity tests has still not been determined. Through the characterization of the mechanisms of adhesion in airless environments, such a pressure limit can be found and rigorously tested.

In this study we address the issues of adhesion on airless bodies by using well-defined conditions which attempt to simulate a lunar environment combined with simple model systems of lunar and spacecraft materials to determine which mechanism above causes the greatest adhesion. To this end, the adhesion between pins of spacecraft materials and a plate of lunar simulant glassy material has been investigated in a UHV environment. The materials can be tested with control of their surface atomic cleanliness and "activation" state, as well as their electrostatic charge. This study includes measurements of adhesion due to both van der Waals forces and electrostatic charging induced by triboelectric charging and electron beam irradiation. The dependence of adhesion forces on time and background pressure will also be addressed. 


\subsection{Experimental Details}

\section{$2.1 \quad$ Materials}

\subsubsection{Ex situ Preparation}

A synthetic noritic volcanic glass (Zybek Advanced Products) was cut, mechanically polished and fashioned to a plate approximately $1 \mathrm{~cm}$ across. Rods of spacecraft materials - a titanium alloy (Ti-6V4Al), polytetrafluoroethylene (PTFE) Teflon, fluorinated ethylene propylene (FEP) Teflon, polycarbonate (PC) - were machined in the form of a pin $2 \mathrm{~cm}$ long with rounded ends (radius $1.6 \mathrm{~mm}$ ). The pin ends were spindle polished as described below and cleaned with high purity ethanol before introduction to a UHV chamber.

Polycarbonate (PC) was wet polished (deionized water) with 9, 3, 1, and $0.3 \mu \mathrm{m} \mathrm{AlO}_{\mathrm{x}}$ paper. Following the mechanical polishing, a vapor polishing procedure was used (Refs. 13 and 14). A dichloromethane vapor was created in a bubbler, which was carried by $\mathrm{N}_{2}$ to the PC pin in a separate flask. Both the bubbler and flask with the PC pin were immersed in a water bath at $30^{\circ} \mathrm{C}\left(\mathrm{p}_{\mathrm{DCM}}=\right.$ 520 torr at $30^{\circ} \mathrm{C}$ ). The $\mathrm{PC}$ pin was exposed to the vapor for $140 \mathrm{sec}$. After $5 \mathrm{~min}$ in air, the pin was baked in an oven at $115^{\circ} \mathrm{C}$ for $10 \mathrm{~min}$. The baking prevented crazing of the PC pin under stress. PTFE Teflon was mechanically polished with PTFE Teflon tape. FEP Teflon was mechanically polished with a FEP sheet. Ti-6-4 was mechanically polished with diamond sheets and paste.

The roughnesses of the volcanic glass plate and the ends of the pins were measured using a Wyko NT1000 optical profiler from Veeco Metrology Group in VSI mode. The approximate root mean square (RMS) roughnesses of the materials before and after adhesion measurement in the UHV chamber are given in Table 1.

\subsubsection{In Situ Preparation and Characterization}

The surfaces of the materials were cleaned by bombardment with Argon ions accelerated to $2 \mathrm{keV}$ from a Varian 981-2043 ion gun. This process removed atmospheric contamination due to water and organic compounds from mineral surfaces and created a number of broken bonds, both of which leave the surface in a state similar to that which dust particles have in an airless body environment. Ti-6-4 was sputtered until no improvement in the $\mathrm{C}$ and $\mathrm{O}$ surface contamination could be discerned using a built-in Auger electron spectrometer before each measurement, unless stated otherwise. Plastic materials were sputtered in 5 min cycles before measurements, when stated in the text. The synthetic volcanic glass was cleaned through ion bombardment prior to all measurements, unless explicitly stated.

\begin{tabular}{|c|c|c|}
\hline \multicolumn{3}{|c|}{$\begin{array}{l}\text { TABLE 1.-APPROXIMATE RMS ROUGH-NE } \\
\text { OF PLATE AND PIN SURFACES BEFORE A } \\
\text { AFTER ADHESION MEASUREMENTS } \\
\text { IN THE UHV CHAMBER }\end{array}$} \\
\hline \multirow[t]{2}{*}{ Material } & \multicolumn{2}{|c|}{$\begin{array}{c}\text { RMS roughness, } \\
\mathrm{nm}\end{array}$} \\
\hline & Before & After \\
\hline Glass & --- & 30 \\
\hline PC & 90 & 150 \\
\hline PTFE & 130 & 180 \\
\hline FEP & 250 & --- \\
\hline Тi-6-4 & --- & 300 \\
\hline
\end{tabular}


TABLE 2.-SURFACE ATOMIC COMPOSITION (IN PERCENT) OF SYNTHETIC VOLCANIC GLASS AND TI-6-4 PIN AS MEASURED BY AES. TI-6-4 PRODUCTION VALUES FOR THE BULK ALLOY ARE INCLUDED

\begin{tabular}{|c|c|c|c|c|c|}
\hline Material: & $\% \mathrm{Mg}$ & $\% \mathrm{Ca}$ & $\% \mathrm{Al}$ & $\% \mathrm{Si}$ & $\% \mathrm{O}$ \\
\hline Synthetic glass & $6.1 \pm 0.8$ & $16.4 \pm 0.7$ & $20.9 \pm 1.7$ & $16.2 \pm 0.8$ & $40.4 \pm 0.9$ \\
\hline & $\% \mathrm{Ti}$ & $\% \mathrm{Al}$ & $\% \mathrm{~V}$ & $\% \mathrm{C}$ & $\% \mathrm{O}$ \\
\hline Ti-6-4 (typical) & $70.0 \pm 3.1$ & $7.5 \pm 0.7$ & $6.5 \pm 0.6$ & $11.8 \pm 2.8$ & $4.2 \pm 1.1$ \\
\hline Ti-6-4 (best attained) & 74.9 & 7.1 & 6.1 & 8.0 & 3.9 \\
\hline Ti-6-4 bulk values & 90 & $5.5-6.75$ & $3.5-4.5$ & ---- & ---- \\
\hline
\end{tabular}

Sample surface composition was monitored using Auger electron spectroscopy (AES) both to define sample cleanliness before adhesion measurement and to determine if any material had been transferred after contact has been broken. AES allows a quantitative analysis of the chemical composition within the first few atomic layers of the surface. Since the investigated minerals and glasses are insulating, the energy of the impinging electron beam was selected so that equilibrium was obtained between impinging and emitted electrons. An electron beam energy of $1.2 \mathrm{keV}$ allowed relevant peaks to be observed but precluded glass sample charging. The plastic pins could not be measured with a beam energy exceeding $550 \mathrm{eV}$ without severe charging effects. Several atomic species, such as $\mathrm{Al}, \mathrm{Mg}, \mathrm{Si}$, and $\mathrm{Ca}$, have Auger electron emission peaks at low energies observable with this primary beam energy. An electron beam energy of $3 \mathrm{keV}$ was used for the Ti-6-4 pin.

The surface composition of the synthetic volcanic glass and Ti-6-4 pin after $\mathrm{Ar}^{+}$ion sputtering are found in Table 2. Oxygen and carbon-containing adsorbates were seen to accumulate within an hour on the Ti-6-4 pin, even in UHV. The volcanic glass accumulated adsorbates at a much lower rate with a few percent $\mathrm{C}$ accumulation over several days.

The plastic materials (PTFE, FEP, PC) displayed a C peak at emission energies around 270 to $285 \mathrm{eV}$. Only trace amounts of $\mathrm{Cl}$ were observed in the $\mathrm{PC}$ pin, with no $\mathrm{Al}$ contamination apparent around $65 \mathrm{eV}$. Otherwise no other atomic species were seen for any of the plastics. Note, however, that fluorine features are beyond the observable spectrum range using a primary electron beam energy of $550 \mathrm{eV}$.

Surface composition of both the pin and glass plate was measured with AES after adhesion measurements, and no transfer of material was observed.

\subsection{Measurement Apparatus}

The measurements were conducted in an oil-free UHV chamber with a base pressure of $<10^{-10}$ torr, allowing experiments to be made on a time scale which prevented significant contamination of the cleaned surfaces. The chamber was equipped with a PHI 15-110A Auger electron spectrometer. A PHI/Perkin-Elmer sputtergun was used for Argon ion bombardment for sample cleaning at an Ar pressure of $5 \times 10^{-5}$ torr and an acceleration voltage of $2 \mathrm{kV}$. Argon bombardment removed hydrocarbons and water adsorbed from the atmosphere on the sample surfaces and simulated the effects of space weathering, leaving the surface in an activated state.

The force of adhesion was measured using a sensitive UHV-compatible torsion balance (Refs. 15 and 16). The balance, shown in Figure 1, provided a direct measure of the pull-off force (referred to as adhesion force) required to separate the synthetic volcanic glass plate from a pin of spacecraft material with a defined radius after they have been brought into contact with a defined force (referred to as load). The load was applied by an approach of the pin towards the glass plate, while the pull-off force was measured through retraction of the pin from the glass plate. The balance was constructed of an arm, approximately $10 \mathrm{~cm}$ long, suspended in the center from a taut wire. The force exerted on the glass plate mounted on one side of the balance arm is directly proportional to the torque on the wire. The torque $\tau$ depends, in turn, on the angle $\theta$ of the arm from its equilibrium position and the spring constant $\kappa$ of the wire as

$$
\tau=-\kappa \theta .
$$




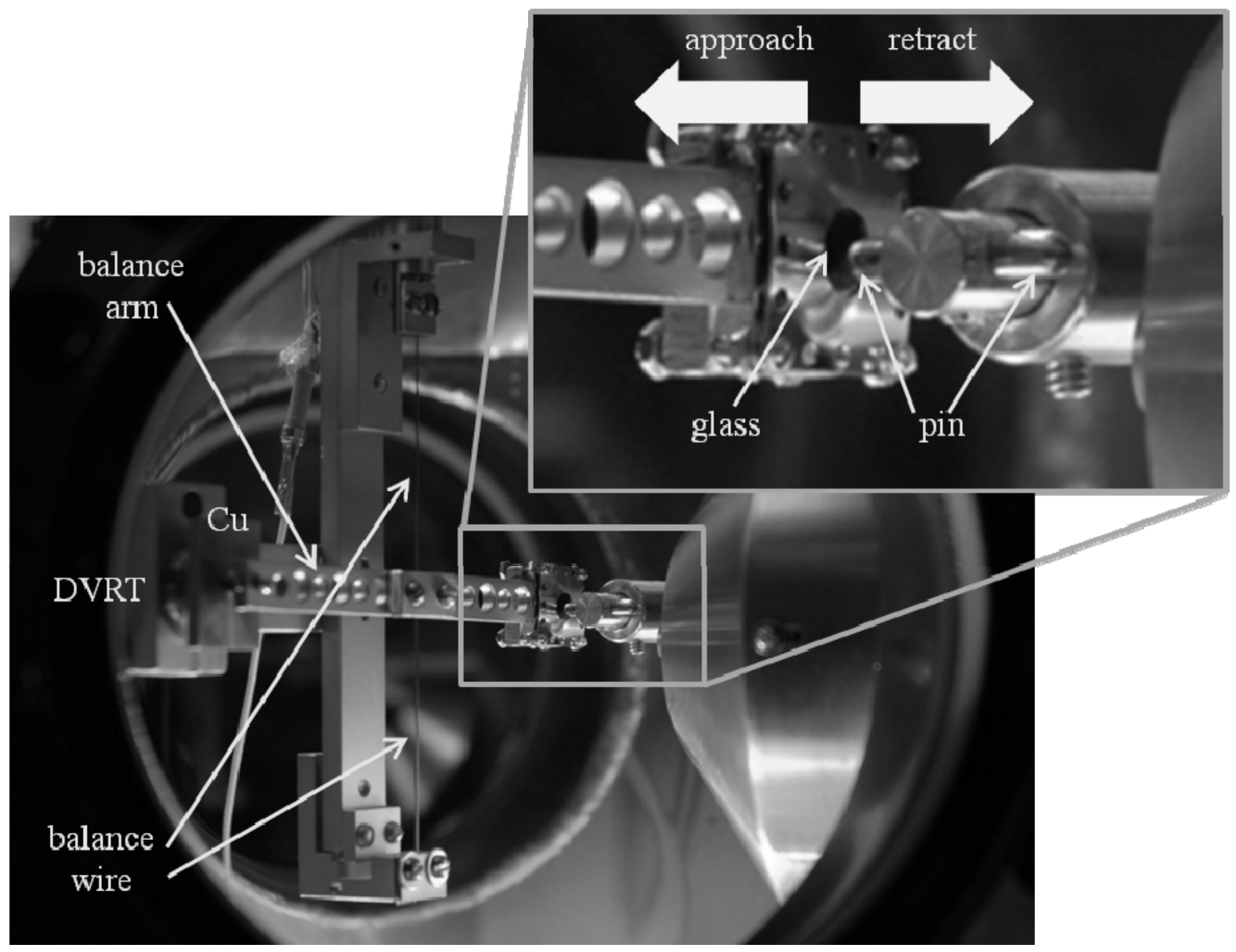

Figure 1.-Torsion balance in UHV chamber with glass plate and PC pin shown magnified in the inset.

The spring constant was calculated from the moment of inertia of the balance arm and the resonant frequency of the balance. The angle was measured by the displacement of a DVRT magnetic reluctance transducer (Microstrain, Inc.) from a copper block mounted on the other side of the balance arm. For more details on the torsion balance, see Reference 10. The lower limit on the pull-off force/adhesion force which could be effectively measured by the torsion balance was about $1 \mu \mathrm{N}$, due to sensor system noise and vibrations (which corresponds to a real balance deflection of $0.0002^{\circ}$ or a displacement of $0.2 \mu \mathrm{m}$ at the glass sample position). The convention used here is to assign positive values for the load the pin exerts on the glass and negative values for the adhesion force observed when pulling the pin away from the glass.

The pins were mounted on the end of a step-motor-driven manipulator with one rotational and three translational degrees of freedom. Two types of mechanical movements were used, slow movement to measure adhesion forces and mechanical striking. Mechanical striking was accomplished by moving the pin to a position $50 \mu \mathrm{m}$ away from the surface, and then quickly approaching and retracting. An example of the displacement of the glass sample on the balance arm during a strike can be seen in Figure 2, panel (a). The kinetic energy of the strike used later in Figure 4 is the kinetic energy gained by the balance as a result of the strike, which, ignoring losses, is equal to the potential energy of the balance at maximum deflection. The potential energy stored in the spring depends on the deflection as

$$
U=-1 / 2 \kappa \theta^{2}
$$




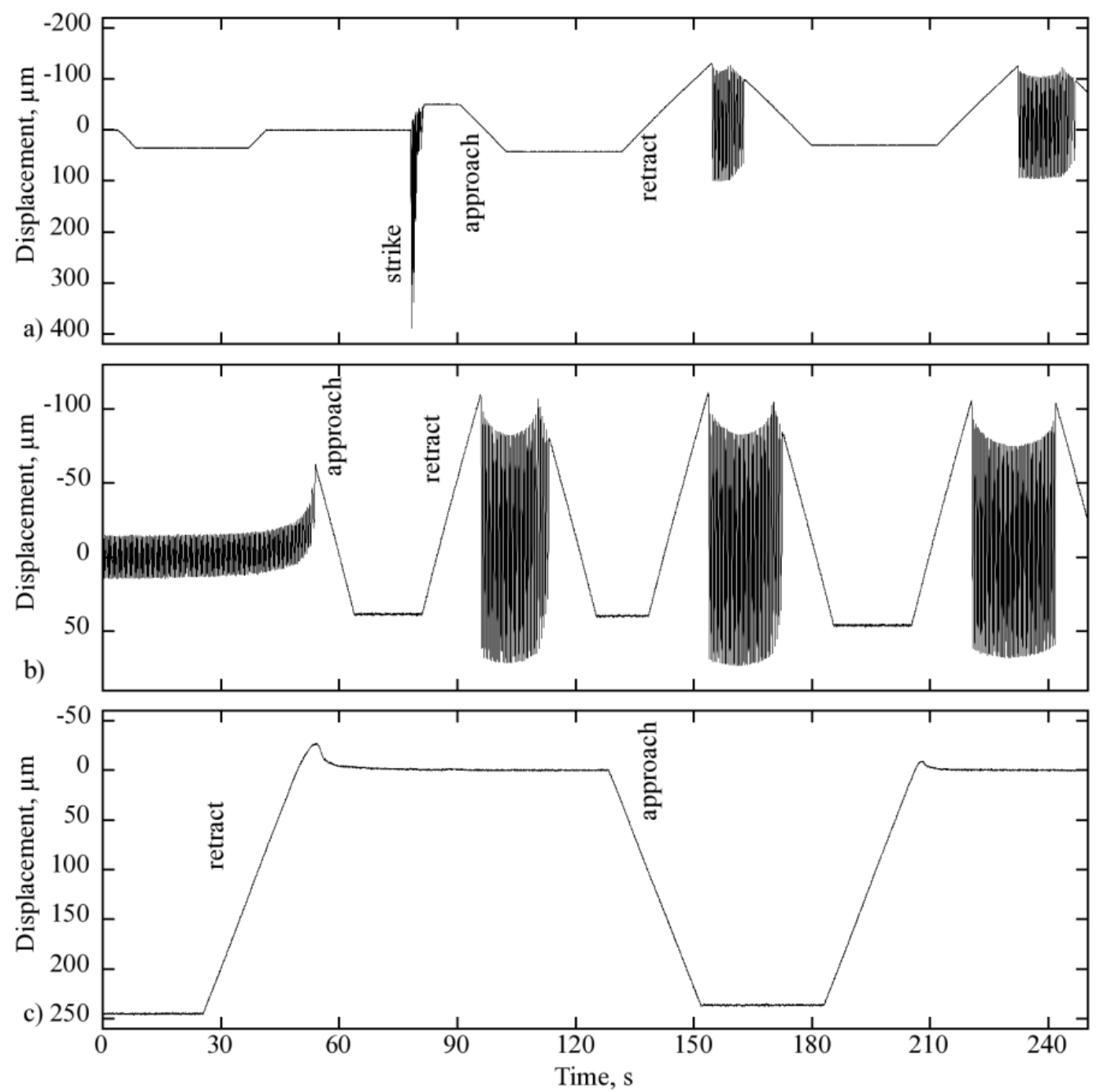

Figure 2.-Displacement of the glass sample on the arm of the torsion balance from the equilibrium position during adhesion measurements.

\subsection{Adhesion Force Measurements}

To measure adhesion forces, slow mechanical movement was used with an approach and retraction speed of $9.3 \mu \mathrm{m} / \mathrm{s}$. Two types of adhesion forces could be observed, electrostatic and van der Waals. Discriminating between the two was simply a matter of watching the position of the balance during approach. Figure 2, panels (b) and (c) demonstrate the differences seen in the movement of the balance. When the pin approached the glass on the balance, the balance would be pulled from equilibrium over a distance of up to several $\mu \mathrm{m}$ in the case of electrostatic forces [panel (b)], whereas a movement of the balance was not observed during approach for van der Waals attraction [panel (c)]. Van der Waals attraction was likely not observed during approach due to its short range nature and the 200-nm limit of balance displacement measurement. Measurements of the adhesion force were made under different loads. Where the magnitude of the load is important, it will be made clear in the text, otherwise a load of around 0.1 to $0.5 \mathrm{mN}$ was used for electrostatic adhesion measurements. The duration of the loads was $30 \mathrm{sec}$ for the van der Waals measurements in Figure 3 whereas the loads were typically maintained $15 \mathrm{sec}$ for cases of electrostatic adhesion. No dependence on the load duration or magnitude was seen for electrostatic adhesion. The adhesion force values given throughout this report are generally the average of three or more contacts with the standard deviation calculated and shown as error bars. 


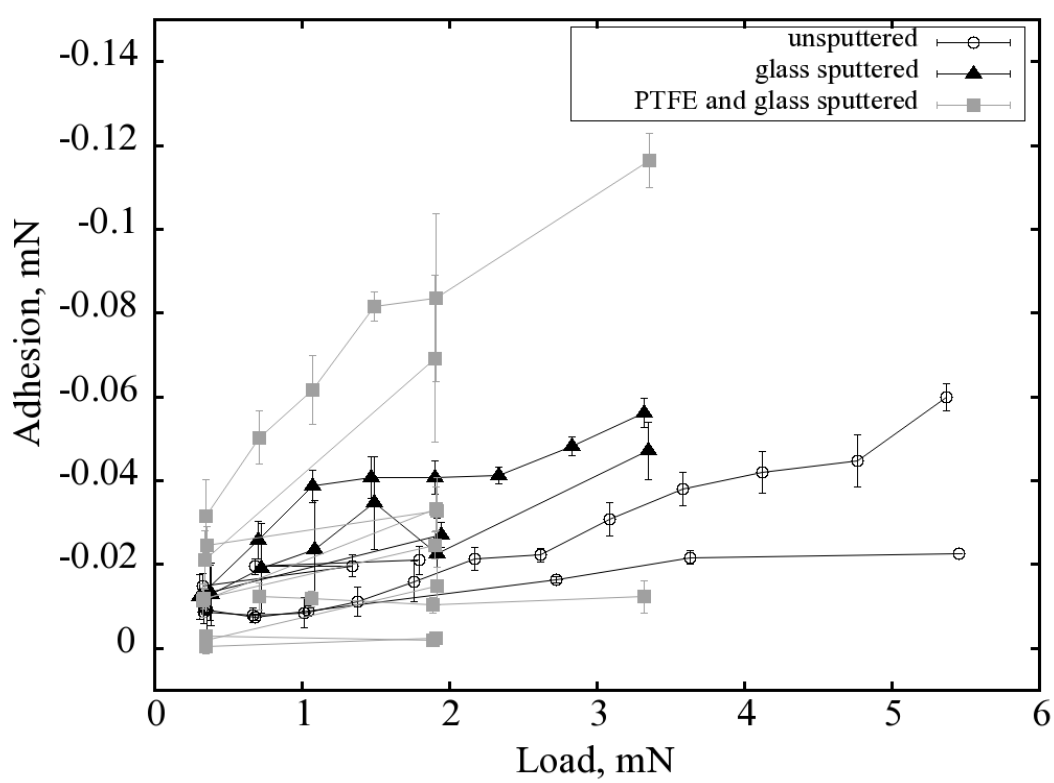

Figure 3.-Adhesion force due to van der Waals interactions as a function of load for a PTFE pin on synthetic volcanic glass. Measurements of different loads at any particular contact position are connected by lines.

\subsection{Results}

An adhesion force due to van der Waals interactions was below the apparatus detection limits for both unsputtered and sputtered glass and pin sample pairs up to a load of at least $10 \mathrm{mN}$ except in the case of the PTFE pin. The van der Waals adhesion force of the PTFE pin on the glass plate for various loads maintained for $30 \mathrm{sec}$ is shown in Figure 3. Data are shown for several particular positions on samples which are unsputtered, on samples for which only the glass has been sputtered, and on samples for which both the PTFE pin and the glass have been sputtered, as indicated by the legend. It can be seen in Figure 3 that the adhesion force depended on the magnitude of the load in a roughly linear fashion for any particular contact position. However, the amount of adhesion varied widely between contact positions, even for similarly treated samples. Leaving the pin attached to the glass at a load of $1.9 \mathrm{mN}$ for a period of $2 \mathrm{hr}$ resulted in an increase in the adhesion force by a factor of 5 to 10 over 30-second-long loads.

Figure 4 displays the electrostatic adhesion force induced between the glass plate and the pins of spacecraft materials by a mechanical strike as a function of the kinetic energy of that strike (as determined from balance deflection). In panel (a), it can be seen that sputtered FEP achieves the greatest electrostatic adhesion forces of greater than $-3 \mathrm{mN}$, even for strike energies on the lower end of the scale. After FEP, sputtered PTFE has the largest resulting electrostatic adhesion from striking, increasing fairly linearly with strike energy from $-0.5 \mathrm{mN}$ for small strike energies to -5 or $6 \mathrm{mN}$ for larger strike energies. Adhesion force values after pin-glass striking for a PTFE sample which was left for two weeks in vacuum (at $10^{-10}$ torr) are found slightly below the values of sputtered PTFE. Below PTFE, sputtered PC has the next strongest induced adhesion force. In panel (b) the adhesion force induced for strikes with PC increased roughly linearly from -0.1 to $-0.7 \mathrm{mN}$. For unsputtered PC, PTFE and FEP samples, little relationship to the strike energy was seen, and all adhesion values remain below $-0.15 \mathrm{mN}$. Each data point displayed in Figure 4 is the average of five or more measurements immediately after the strike at the strike position. Note that although the adhesion force values vary widely for different strikes, the value measured for any particular strike is fairly precise. 

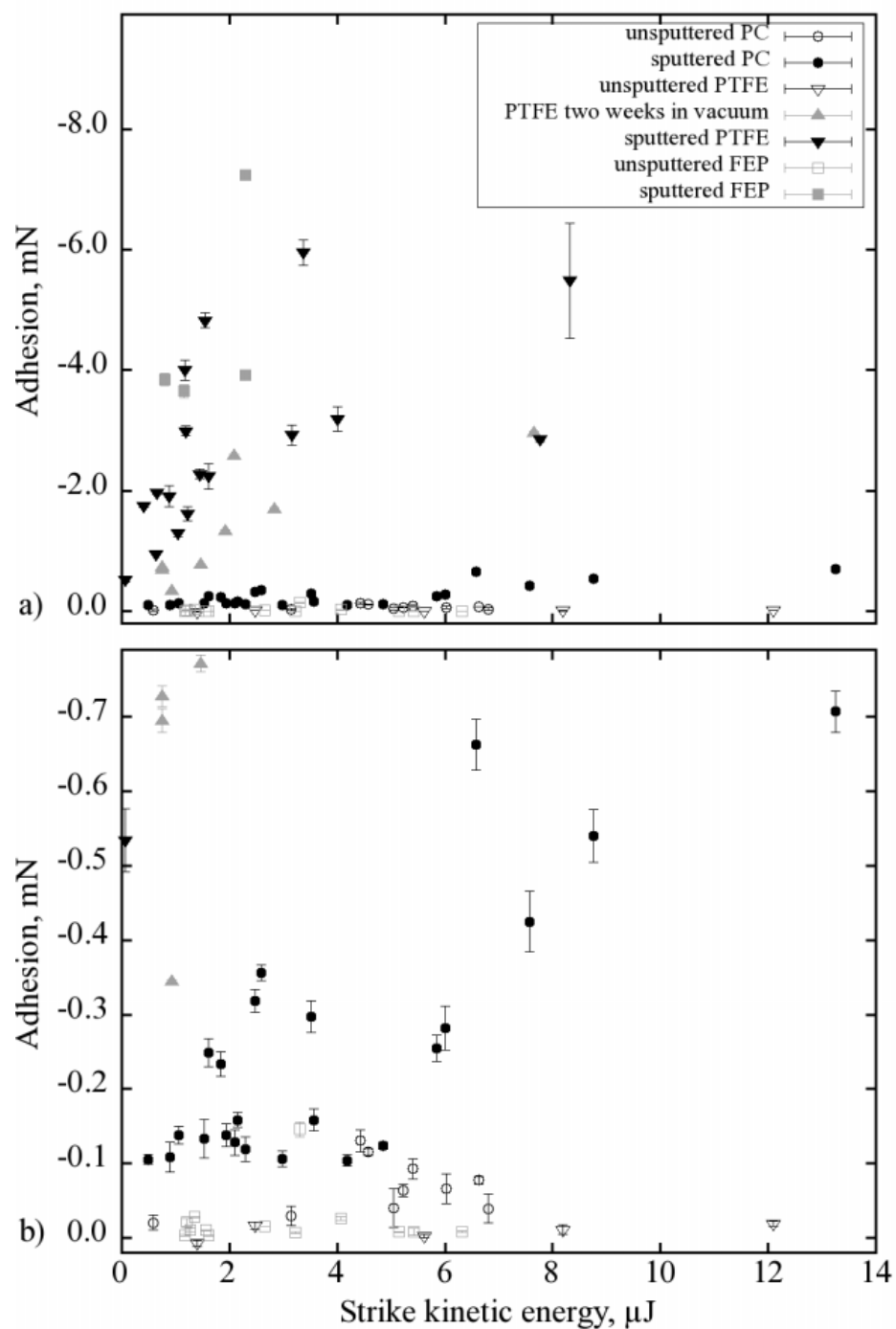

Figure 4.-Electrostatic adhesion achieved as a function of kinetic energy transferred during pin-glass strike. Panel (b) shows an expanded ordinate (adhesion scale) for the data of panel (a).

Ti-6-4 displayed no induced electrostatic adhesion for any mechanical strike energy both in sputtered and unsputtered states (the Ti-6-4 pin is grounded). Electrostatic adhesion could, however, be induced between the Ti-6-4 pin and glass plate by irradiating the glass plate with a $5 \mathrm{keV}$ electron beam from the Auger spectrometry system. (The electron beam was rastered over a 2 by $3 \mathrm{~mm}$ area and had a nominal beam current of $1.2 \mathrm{~mA}$. No change in the surface composition was observed with AES after electron beam irradiation.) Figure 5 shows the adhesion force versus irradiation time of the glass for both pins which have been sputtered less than an hour previously as well as pins which had been allowed to accumulate adsorbates (AES showed carbon and oxygen accumulation). It is apparent from the figure that the adhesion force attained through electron beam irradiation varied over two orders of magnitude and did not depend on the total electron dose. Electron beam energies of $500 \mathrm{eV}$ to $4 \mathrm{keV}$ were also used, but did not induce measureable adhesion. 


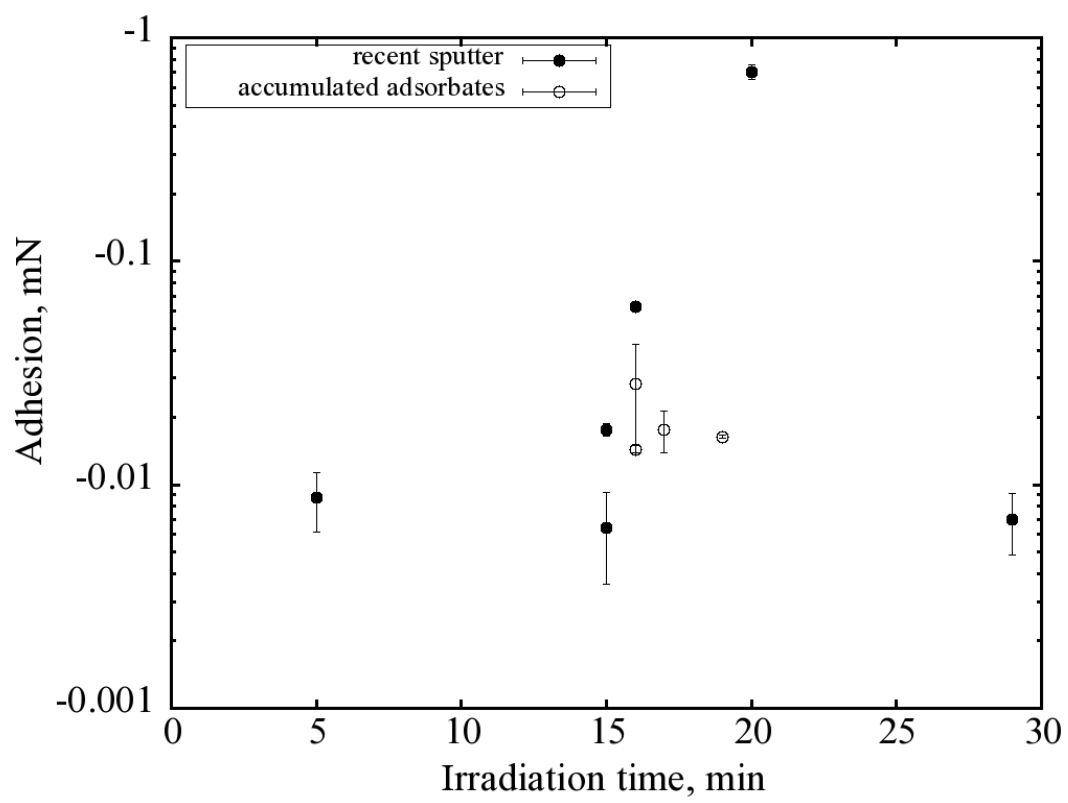

Figure 5.-Adhesion force induced between Ti-6-4 pin and volcanic glass by electron beam bombardment of glass as a function of bombardment time.

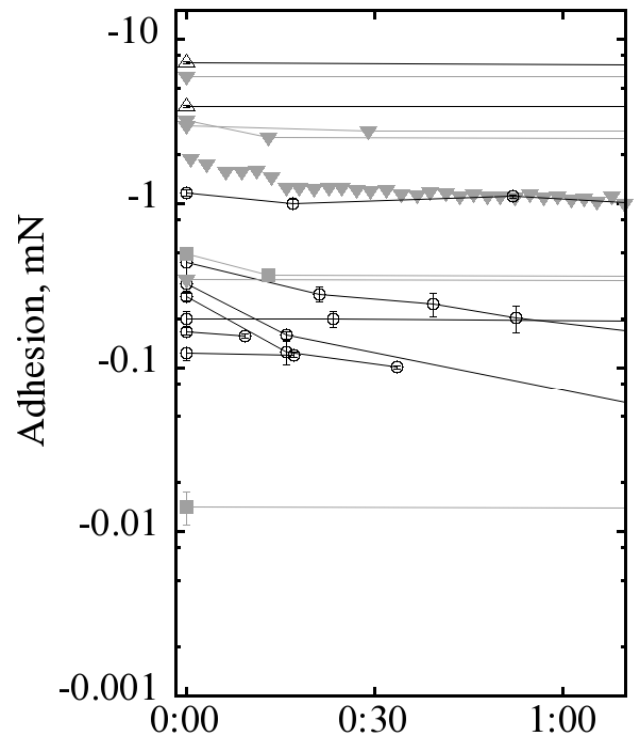

a)

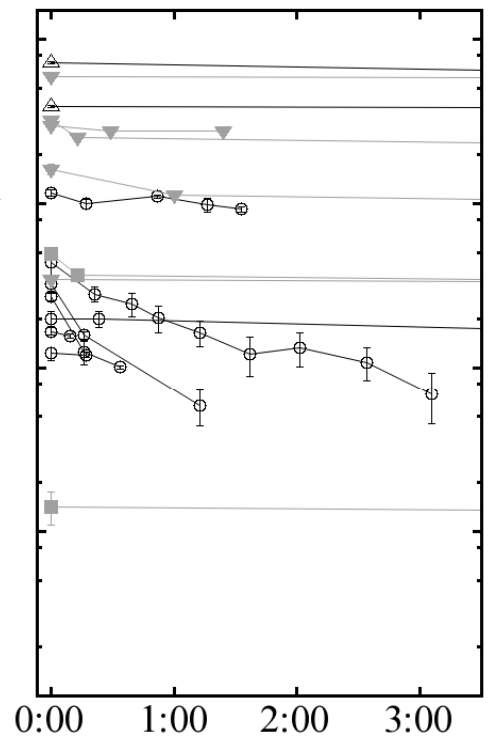

b)

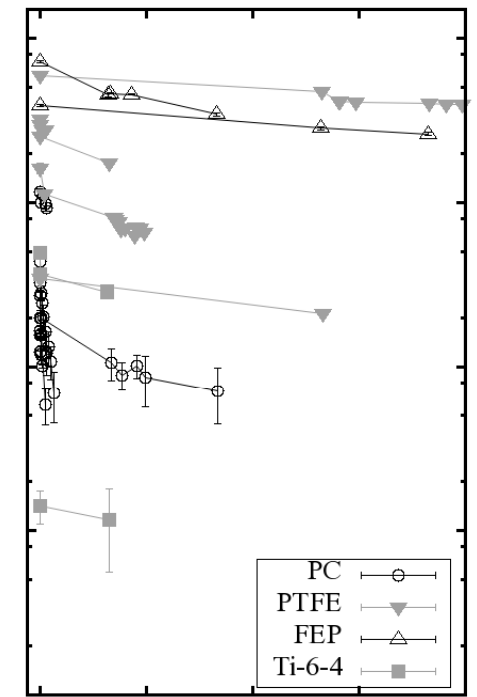

0:00 24:00 48:00 72:00 96:00

c) Time, $\mathrm{h}$

Figure 6.-Adhesion dependence on time for different spacecraft materials and different electrostatic adhesion values. Panel (a) shows an expanded abscissa (time scale) for the data of panel (b), which, in turn, is an expansion of panel (c). Values measured after any particular strike are connected by lines.

The persistence with time of the electrostatic adhesion force induced by strikes in UHV was measured for many individual strikes over periods ranging from hours to days. Figure 6 contains a summary of the time dependence found for electrostatic adhesion between the glass and different materials starting from various initial adhesion force values. In panels (a) and (b), it can be seen that the adhesion force measured for the different materials dropped quickly in the first few minutes to hours. This drop was roughly exponential for all materials and strengths of adhesion force. In panel (c), it can be seen that the adhesion values dropped less quickly after the first hours and remained significant over a period of days. 


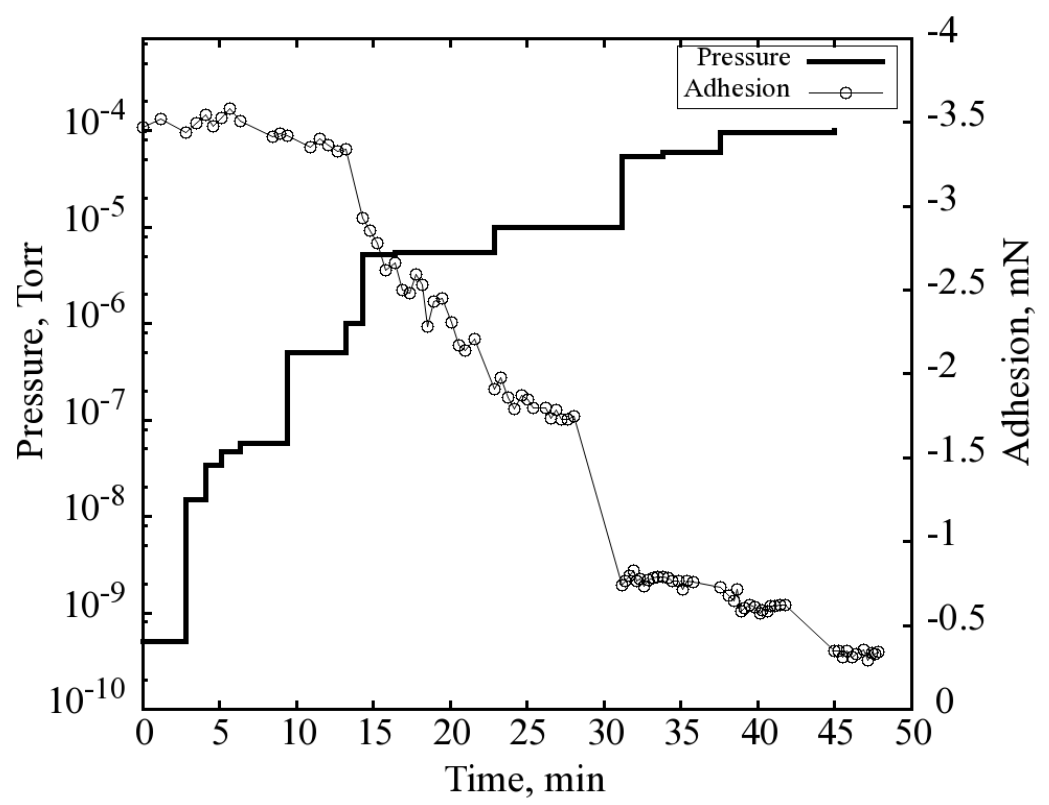

Figure 7.-FEP adhesion as a function of time during an increase of Argon pressure.

To test the robustness of the electrostatic adhesion with variation of background pressure, Argon gas was leaked into the UHV chamber while measuring the adhesion force of an FEP pin to the glass after striking. Figure 7 displays the adhesion force and the Ar pressure as a function of time. The adhesion force remained around $-3.5 \mathrm{mN}$ until an Ar pressure of $5 \times 10^{-6}$ torr was reached, at which point the adhesion force dropped quickly. Another drop was seen as the Ar pressure was increased to $5 \times 10^{-5}$ torr. This drop appeared as a discontinuity due to the inability to measure adhesion force when further opening the Ar valve. At a pressure of $1 \times 10^{-4}$ torr, the limit of the ionization gauge, the adhesion force had dropped by an order of magnitude from its original value.

\subsection{Discussion}

The results above show that non-electrostatic adhesion forces between synthetic volcanic glass and pins of spacecraft materials are below $1 \mu \mathrm{N}$ for this contact geometry regardless of the atomic cleanliness of the pins and glass, except in the case of PTFE. PTFE is known to have a small surface free energy. Therefore, the small adhesion seen in the PTFE due to van der Waals forces presumably occurs due to deformation of the asperities and curvature of the PTFE pin to create a larger contact surface with the glass, as evidenced by the increase in adhesion force with load and time. The behavior of these materials is in stark contrast to results obtained by Miyoshi et al., for silicon carbide/aluminum and sapphire/ aluminum material pairs, where a strong adhesion force was observed for sputtered, atomically clean surfaces (Refs. 10 and 17). In the case of silicon carbide with aluminum, the chemical bond formed between the two materials was sufficient to cause a transfer of aluminum to the silicon carbide surface.

Significant electrostatic adhesion was, however, observed between the spacecraft materials and the volcanic glass. In the case of the plastics (PC, PTFE, FEP), triboelectric charge transfer occurred through a mechanical strike of the pin against the volcanic glass. The magnitude of this charge transfer for any particular material depended to a great extent on the atomic cleanliness of the surface. The electrostatic adhesion induced by striking was seen to increase by one to two orders of magnitude for pins which had been sputtered for 5 min or more. 
The electrostatic adhesion induced per strike energy on sputtered pins was roughly an order of magnitude greater for the Teflon pins than for the PC pin, with FEP slightly greater than PTFE. Consultation of triboelectric tables, which indicate rough charge transfer expected for two materials in mechanical contact, show that soda-lime glass (presumably similar to the synthetic volcanic glass) lies towards the positive side of the triboelectric series, whereas PC lies on the negative side of the series. Teflon is generally found at the far most end of the negative side as a result of the strong electron affinity of the fluorine it contains. In light of the triboelectric expectations, the Teflon and PC pins are presumably negatively charged after striking, with a greater transfer of electrons to the Teflon than to the PC.

The strike energies used in this study correspond roughly to the kinetic energy a 2-mm or larger particle has after a drop of $1 \mathrm{~m}$ on the lunar surface. The resulting electrostatic adhesion force expected is then 1000 times the gravitational force acting on that 2-mm particle. In the range measured here, the adhesion force apparently scales linearly with the strike energy. Lee has stated that particle adhesion will involve electrostatic interaction on the lunar surface if the particles are pre-charged (e.g., through the photoelectric effect) (Ref. 18). If the triboelectric scaling behavior persists down to smaller orders of magnitude, then electrostatic adhesion due to triboelectric charge transfer by dust particle impact will also present a significant source of adhesion.

The electrostatic adhesion induced by charging the glass plate through electron beam irradiation likely resulted in a positive charge on the glass due to more secondary electrons being ejected from the material than the impinging electron beam provides. Oechsner observed secondary electron yields greater than 1 for silica glass at comparable electron beam energies (Ref. 19). The mechanism of attraction of the Ti-6-4 pin to the charged glass will be due to the image charge induced in the metallic pin. Due to asperities on the surface of the Ti-6-4 pin, the glass was not discharged through contact with the pin. Considering the expectation of a positive charge generally present on the illuminated side of an airless body due to the photoelectric effect, electrostatic adhesion of glassy regolith materials to metallic surfaces can be expected. Further, Walton has postulated that the charge on individual dust particles is distributed in inhomogeneous patches of charge (Ref. 8), which, coupled with the uneven surfaces of many dust particles, will lead to little chance of discharge through contact with a conductive material.

Surface cleanliness has been shown to be an important factor for the triboelectric charge transfer. After the initial $\mathrm{Ar}^{+}$ion sputter cleaning of the surfaces used in this study, the cleanliness will depend on the quality of the vacuum environment. Likewise, once the charge transfer has taken place, the persistence of the charge on the surface and, hence, the electrostatic adhesion depends on the quality of the vacuum environment. Strong electrostatic adhesion was observed here to persist for a period of at least several days with no significant degradation in a vacuum of $10^{-10}$ torr. Once the charged pin has been exposed to Argon gas at pressures around $10^{-5}$ torr, a drastic drop in the adhesion force occurs. In a typical unbaked vacuum system, the largest constituent of the remaining gas is water, which will likely discharge any charged surfaces at lower pressures than Argon. Considering that the surfaces of airless bodies are in a UHV environment under conditions which result in atomically clean materials, high fidelity tests of dust adhesion should be made with the best pressure possible, but at least $<10^{-6}$ torr, and should also include a cleaning step of any exposed surfaces.

\subsection{Conclusion}

We have found that van der Waals forces between a synthetic volcanic glass plate and pins of Ti-6-4, polycarbonate (PC), and FEP are negligible, and very small for PTFE, even for atomically clean samples. However, large adhesion forces are obtained if the pin or plate materials are charged. Triboelectric charge transfer occurs when the plastic pin materials (PC, PTFE, and FEP) are struck against the glass plate. On striking, electrons flow presumably from the glass to the plastic. The charge transfer is much higher when the surfaces have been activated by cleaning the surface of the pin of the contaminant layer by sputtering with $\mathrm{Ar}^{+}$ions. We expect that material surfaces on the moon, and other airless bodies, will be in this atomically clean and active state because of the constant bombardment by the solar wind and the extremely high vacuum. 
Triboelectric charge transfer is greater to the Teflon than to the polycarbonate because of the fluorine in the Teflon, which has a very high affinity for electrons. The greater charge transfer to Teflon implies that on the surface of the moon, Teflon surfaces will tend to accumulate dust at a higher rate than polycarbonate surfaces and a much higher rate than metallic surfaces. In addition, once they get dust on them we can expect that Teflon surfaces will be harder to clean.

The implication of these results is that dust mitigation techniques should be targeted at electrostatic interactions, particularly when plastic materials must be used. The results may explain, for example, why workfunction matching coatings (which lower charge transfer) were more effective than textured coatings (which lower surface area and, hence, van der Waals forces) at lowering the adhesion of dust to the surfaces of silver-backed FEP sheets (AgFEP) in a recent study (Ref. 20).

Furthermore, tests of materials and spacecraft systems to determine their performance and endurance in dusty lunar and airless body environments should presume that the atomic cleanliness of the materials and the pressure of the test system will play an important role in the fidelity of the results.

\section{References}

1. Gaier, J.R., and Jaworske, D.A., "Lunar Dust on Heat Rejection System Surfaces: Problems and Prospects," NASA/TM-2007-214814, 2007.

2. O'Brien, B.J., Freden, S.C., and Bates, J.R., "Degradation of Apollo 11 Deployed Instruments Because of Lunar Module Ascent Effects," Journal of Applied Physics, Vol. 41, No. 11, 1970, pp. 4538-4541.

3. Katzan, C.M., Brinker, D.J., and Kress, R., "The Effects of Lunar Dust Accumulation on the Performance of Photovoltaic Arrays," NASA Glenn Research Center, Document ID 19910020924, Brook Park, OH, 1991.

4. Gaier, J.R., "The Effects of Lunar Dust on EVA Systems During the Apollo Missions," NASA/TM-2005-213610/REV1, 2005.

5. Murphy Jr., T.W., Adelberger, E.G., Battat, J.B.R., Hoyle, C.D., McMillan, R.J., Michelsen, E.L., Samad, R.L., Stubbs, C.W., and Swanson, H.E., "Long-Term Degradation of Optical Devices on the Moon," Icarus, Vol. 208, No. 1, 2010, pp. 31-35.

6. Vander Wal, R.L., "Lunar Dust Chemical, Electrical, and Mechanical Reactivity: Simulation and Characterization," The National Center for Space Exploration Research, NASA/CR - 2008-215431, Cleveland, OH, Oct. 2008.

7. Gaier, J.R., "Regolith Activation on the Lunar Surface and Its Ground Test Simulation," NASA/TM-2009-215648, 2009.

8. Walton, O.R., "Adhesion of Lunar Dust," Grainflow Dynamics, Inc., NASA/CR—2007-214685, Livermore, CA, Apr. 2007.

9. Gaier, J.R., and Sechkar, E.A., "Lunar Simulation in the Lunar Dust Adhesion Bell Jar," NASA/TM-2007-214704, 2007.

10. Miyoshi, K., Pohlchuck, B., Whitle, N.C., Hector, L.G., Jr., and Adams, J., "Properties Data for Adhesion and Surace Chemistry of Aluminum," NASA TM-1998-206638, 1998.

11. Katzan, C.M., and Edwards, J.L., "Lunar Dust Transport and Potential Interactions with Power System Components," NASA, Document ID 19920002733, NASA CR-4404, Brook Park, OH, Nov. 1991.

12. Sickafoose, A.A., Colwell, J.E., Horányi, M., and Robertson, S., "Photoelectric Charging of Dust Particles in Vacuum," Physical Review Letters, Vol. 84, No. 26, 2000, pp. 6034-6037.

13. McGinniss, V.D., "Vaporous Solvent Treatment of Thermoplastic Substrates," U.S. Patent No. 4,529,563, July 1985.

14. Lee, K. S.-K., "Large Core Polymer Optical Backplanes for Fluorescence Detection," Master's Thesis, Dept. of Electrical Engineering and Computer Science, Massachusetts Institute of Technology, Cambridge, MA, 2006. 
15. Miyoshi, K., "Design, Development, and Applications of Novel Techniques for Studying Surface Mechanical Properties," NASA TM-101959, 1989.

16. Miyoshi, K., Maeda, C., and Masuo, R., "Development of a Torsion Balance for Adhesion Measurements," NASA TM-100799, 1988.

17. Miyoshi, K., "Uses of Auger and X-ray Photoelectron Spectroscopy in the Study of Adhesion and Friction," NASA TM-103266, 1991.

18. Lee, L.-H., "Adhesion and Cohesion Mechanisms of Lunar Dust on the Moon's Surface," Fundamentals of Adhesion and Interfaces, edited by D.S. Rimai, L.P. DeMejo and K.L. Mittal, VSP BV, Utrecht, Netherlands, 1995, pp. 73-94.

19. Oechsner, H., "Analysis of Electrically Non-conducting Sample Structures with Electron and Mass Spectroscopic Methods," Thin Solid Films, Vol. 341, No. 1-2, 1999, pp. 105-108.

20. Gaier, J.R., Waters, D.L., Misconin, R.M., Banks, B.A., and Crowder, M., "Evaluation of Surface Modification as a Lunar Mitigation Strategy for Thermal Control Surfaces," 41st International Conference on Environmental Systems, American Institute of Aeronautics and Astronautics, Reston, VA 2011, AIAA-2011-5183. 


\begin{tabular}{|c|c|c|}
\hline \multicolumn{2}{|c|}{ REPORT DOCUMENTATION PAGE } & $\begin{array}{l}\text { Form Approved } \\
\text { OMB No. 0704-0188 }\end{array}$ \\
\hline \multicolumn{3}{|c|}{ 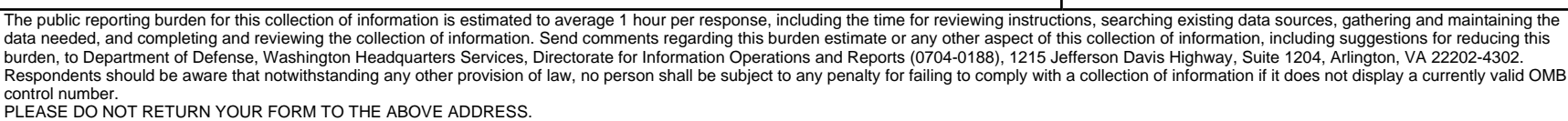 } \\
\hline $\begin{array}{l}\text { 1. REPORT DATE (DD-MM-YYYY) } \\
01-01-2012\end{array}$ & $\begin{array}{l}\text { 2. REPORT TYPE } \\
\text { Technical Memorandum }\end{array}$ & 3. DATES COVERED (From - To) \\
\hline \multirow{3}{*}{\multicolumn{2}{|c|}{$\begin{array}{l}\text { 4. TITLE AND SUBTITLE } \\
\text { Adhesion Between Volcanic Glass and Spacecraft Materials in an A }\end{array}$}} & 5a. CONTRACT NUMBER \\
\hline & & 5b. GRANT NUMBER \\
\hline & & 5c. PROGRAM ELEMENT NUMBER \\
\hline \multirow{3}{*}{\multicolumn{2}{|c|}{$\begin{array}{l}\text { 6. AUTHOR(S) } \\
\text { Berkebile, Stephen; Street, Kenneth, W., Jr.; Gaier, James, R. }\end{array}$}} & 5d. PROJECT NUMBER \\
\hline & & 5e. TASK NUMBER \\
\hline & & $\begin{array}{l}\text { 5f. WORK UNIT NUMBER } \\
\text { WBS 780896.04.06.02.03 }\end{array}$ \\
\hline \multicolumn{2}{|c|}{$\begin{array}{l}\text { 7. PERFORMING ORGANIZATION NAME(S) AND ADDRESS(ES) } \\
\text { National Aeronautics and Space Administration } \\
\text { John H. Glenn Research Center at Lewis Field } \\
\text { Cleveland, Ohio 44135-3191 }\end{array}$} & $\begin{array}{l}\text { 8. PERFORMING ORGANIZATION } \\
\text { REPORT NUMBER } \\
\text { E-17904 }\end{array}$ \\
\hline \multirow{2}{*}{\multicolumn{2}{|c|}{$\begin{array}{l}\text { 9. SPONSORING/MONITORING AGENCY NAME(S) AND ADDRESS(ES) } \\
\text { National Aeronautics and Space Administration } \\
\text { Washington, DC 20546-0001 }\end{array}$}} & $\begin{array}{l}\text { 10. SPONSORING/MONITOR'S } \\
\text { ACRONYM(S) } \\
\text { NASA }\end{array}$ \\
\hline & & $\begin{array}{l}\text { 11. SPONSORING/MONITORING } \\
\text { REPORT NUMBER } \\
\text { NASA/TM-2012-217221 }\end{array}$ \\
\hline \multicolumn{3}{|c|}{$\begin{array}{l}\text { 12. DISTRIBUTION/AVAILABILITY STATEMENT } \\
\text { Unclassified-Unlimited } \\
\text { Subject Category: } 91 \\
\text { Available electronically at http://www.sti.nasa.gov } \\
\text { This publication is available from the NASA Center for AeroSpace Information, 443-757-5802 }\end{array}$} \\
\hline
\end{tabular}

\section{SUPPLEMENTARY NOTES}

\section{ABSTRACT}

The successful exploration of airless bodies, such as the Earth's moon, many smaller moons of the outer planets (including those of Mars) and asteroids, will depend on the development and implementation of effective dust mitigation strategies. The ultrahigh vacuum environment (UHV) on the surfaces of these bodies, coupled with constant ion and photon bombardment from the Sun and micrometeorite impacts (space weathering), makes dust adhesion to critical spacecraft systems a severe problem. As a result, the performance of thermal control surfaces, photovoltaics and mechanical systems can be seriously degraded even to the point of failure. The severe dust adhesion experienced in these environments is thought to be primarily due to two physical mechanisms, electrostatic attraction and high surface energies, but the dominant of these has yet to be determined. The experiments presented here aim to address which of these two mechanisms is dominant by quantifying the adhesion between common spacecraft materials (polycarbonate, FEP and PTFE Teflon, (DuPont) Ti-6-4) and a synthetic noritic volcanic glass, as a function of surface cleanliness and triboelectric charge transfer in a UHV environment. Adhesion force has been measured between pins of spacecraft materials and a plate of synthetic volcanic glass by determining the pull-off force with a torsion balance. Although no significant adhesion is observed directly as a result of high surface energies, the adhesion due to induced electrostatic charge is observed to increase with spacecraft material cleanliness, in some cases by over a factor of 10, although the increase is dependent on the particular material pair. The knowledge gained by these studies is envisioned to aid the development of new dust mitigation strategies and improve existing strategies by helping to identify and characterize mechanisms of glass to spacecraft adhesion for norite volcanic glass particles. Furthermore, the experience of the Apollo missions revealed that dust mitigation strategies must be subjected to high fidelity tests. To facilitate the effectiveness of ground-based testing of mitigation strategies, the issue of a pressure limit for high fidelity tests will be addressed.

\section{SUBJECT TERMS}

Thermal control; Surface properties; Adhesion; Particles; Dust; Minerals; Surface properties; Surface energy

\begin{tabular}{|c|c|c|c|c|c|}
\hline \multicolumn{3}{|c|}{ 16. SECURITY CLASSIFICATION OF: } & \multirow{2}{*}{$\begin{array}{l}\text { 17. LIMITATION OF } \\
\text { ABSTRACT } \\
\text { UU }\end{array}$} & \multirow{2}{*}{$\begin{array}{l}\text { 18. NUMBER } \\
\text { OF } \\
\text { PAGES } \\
19\end{array}$} & \multirow{2}{*}{$\begin{array}{l}\text { 19a. NAME OF RESPONSIBLE PERSON } \\
\text { STI Help Desk (email:help@sti.nasa.gov) } \\
\text { 19b. TELEPHONE NUMBER (include area code) } \\
\text { 443-757-5802 }\end{array}$} \\
\hline $\begin{array}{l}\text { a. REPORT } \\
\text { U }\end{array}$ & $\begin{array}{l}\text { b. ABSTRACT } \\
\text { U }\end{array}$ & $\begin{array}{l}\text { c. THIS } \\
\text { PAGE } \\
\text { U }\end{array}$ & & & \\
\hline
\end{tabular}



